\title{
x
}

\section{Methane Gas Sensing Properties of the Zinc Oxide Nanowhisker-derived Gas Sensor}

\author{
Hyung-Sin Moon \\ Bump Engineering Team, DDI Engineering Group, Nepes Corporation, Cheongwon 363-885, Korea \\ Sung-Eun Kim and Woo-Chang Choi ${ }^{\dagger}$ \\ MEMS/NANO Fabrication Center, Busan Techno-Park, Busan 609-735, Korea
}

Received January 17, 2012; Revised February 23, 2012; Accepted February 28, 2012

\begin{abstract}
A low power methane gas sensor with microheater was fabricated by silicon bulk micromachining technology. In order to heat up the sensing layer to operating temperature, a platinum $(\mathrm{Pt}$ ) micro heater was embedded in the gas sensor. The line width and gap of the microheater was $20 \mu \mathrm{m}$ and $4.5 \mu \mathrm{m}$, respectively. Zinc oxide (ZnO) nanowhisker arrays were grown on a sensor from a ZnO seed layer using a hydrothermal method. A $200 \mathrm{ml}$ aqueous solution of 0.1 mol zinc nitrate hexahydrate, $0.1 \mathrm{~mol}$ hexamethylenetetramine, and $0.02 \mathrm{~mol}$ polyethylenimine was used for growing $\mathrm{ZnO}$ nanowhiskers. Temperature distribution of the sensor was analyzed by infrared thermal camera. The optimum temperature for highest sensitivity was found to be $250^{\circ} \mathrm{C}$ although relatively high (64\%) sensitivity was obtained even at as low a temperature as $150^{\circ} \mathrm{C}$. The power consumption was $72 \mathrm{~mW}$ at $250^{\circ} \mathrm{C}$, and only $25 \mathrm{~mW}$ at $150^{\circ} \mathrm{C}$.
\end{abstract}

Keywords: Gas sensor, Microheater, Zinc oxide, Nanowhiskers, Methane

\section{INTRODUCTION}

Recent research show, methane to be a gas that affects global warming 20 times more severely than carbon dioxide. It is explosive, due to its high volatility and flammability in air [1]; and in closed areas, methane gas may cause suffocation. Therefore development of a reliable and economical methane gas sensor is needed. Micro gas sensors using CMOS or CMOS-MEMS technology are being developed and applied because of their small size, light weight, low power, fast response, suitability to mass production, and low production cost [2,3].

Oxide semiconductor gas sensors have high sensitivity and a fast response speed compared with other sensors. They are easy to manufacture, and the addition of appropriate catalysts allows the sensors to be selective to specific gases [4-7]. Their operation

${ }^{\dagger}$ Author to whom all correspondence should be addressed: E-mail: future2014@btp.or.kr

Copyright $\odot 2012$ KIEEME. All rights reserved.

This is an open-access article distributed under the terms of the Creative Commons Attribution Non-Commercial
License (http://creativecommons.org/licenses/by-nc/3.0) which permits unrestricted noncommercial use License (http://creativecommons.org/licenses/by-nc/s to which permits unrestricted
distribution, and reproduction in any medium, provided the original work is properly cited. is mainly based on the change of conductivity of an oxide surface caused by adsorption and desorption, which occurs when the reactive gas is exposed to sensing film. In order to measure gas sensitivity, the temperature of the sensing material should be maintained at over $300^{\circ} \mathrm{C}$ uniformly through the gas adsorption and desorption processes [8]. A heater is necessary for this reason; this results in a massive power consumption problem [9].

To reduce the power and increase the sensitivity of the gas sensor, nanotechnology-derived nano-sized gas sensing membranes have been developed. The detection method of a semiconductor-based gas sensor is based on surface reaction. Since nanomaterial-based sensors have a large detection surface area, they have relatively higher sensitivity and lower power consumption compared to bulk sensors [10-12]. ZnO can be synthesized into nanotube, nanowire or nanorod forms, depending on synthesis technique and post-processing. By applying different catalysts, they may exhibit selectivity for certain types of gas.

We have developed a gas sensor for methane gas sensing using bulk micromachining technologies, utilizing a $\mathrm{ZnO}$ nanowhiskerderived sensing layer and a platinum (Pt) micro-heater. Using the pulsed laser deposition (PLD) method, a $\mathrm{ZnO}$ seedlayer was 


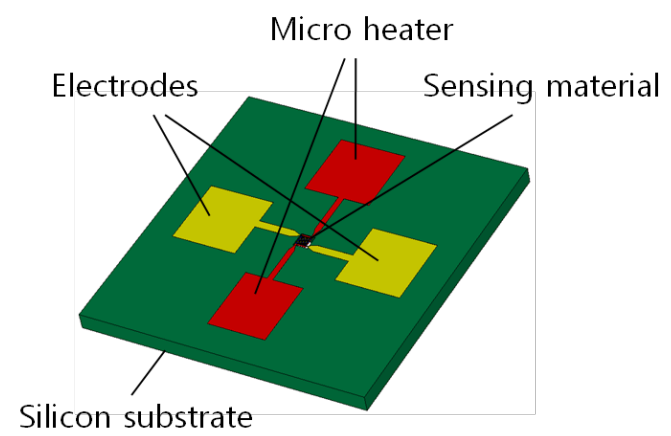

Fig. 1. Schematic diagram of the gas sensor structure.

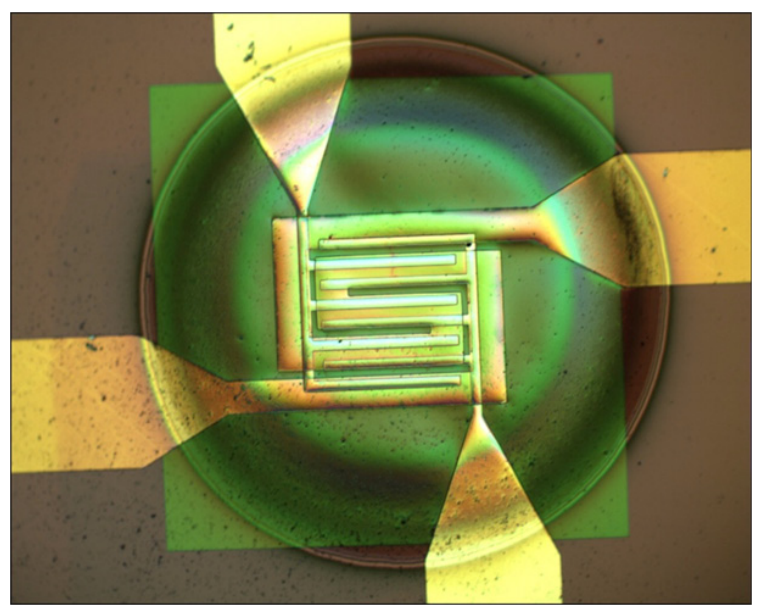

Fig. 2. Optical image of fabricated sensor.

deposited and $\mathrm{ZnO}$ nano-whiskers were hydrothermally synthesized from the $\mathrm{ZnO}$ seed layer. To enhance the sensing property of methane gas, palladium (Pd) and silver (Ag) were deposited on the $\mathrm{ZnO}$ nanowhisker using an e-beam evaporator.

\section{SENSOR FABRICATION}

Figure 1 shows a schematic diagram of the proposed gas sensor. A p-type (100) double-side polished silicon wafer with resistivity of $6 \Omega \cdot \mathrm{cm}$ and thickness of $495 \mu \mathrm{m}$ was used as a substrate. Low stress nitride with a thickness of $1,600 \AA$ was then deposited on the substrate using a low pressure chemical vapor deposition (LPCVD) method. To define a wet etching mask, silicon nitride was etched using reactive ion etcher (RIE). For a diaphragm structure, the back of the substrate was etched with $30 \mathrm{wt} \%$ potassium hydroxide (KOH). The microheater and sensing electrode were defined using photolithography. Titanium (Ti) and platinum (Pt) materials were deposited and annealed to use as a microheater. Their thickness was $200 \AA$ and 2,000 $\AA$, respectively. To insulate the microheater and sensing electrode, silicon dioxide with a thickness of $4,000 \AA$ was deposited using a plasma enhanced chemical vapor deposition (PECVD) method. After deposition of a passivation layer, a gold $(\mathrm{Au})$ electrode was patterned using photolithography and an e-beam evaporator.

A ZnO seed layer of 1,000 A was deposited on the membrane's active layer by a pulsed laser deposition (PLD) method, as shown in Fig 2. Figure 3 shows the $\mathrm{x}$-ray diffraction curves of $\mathrm{ZnO}$ seed layer deposited on the silicon substrate. The dominant peak observed at $2 \theta=34.4^{\circ}$ was (002)-oriented $\mathrm{ZnO}$, and the full

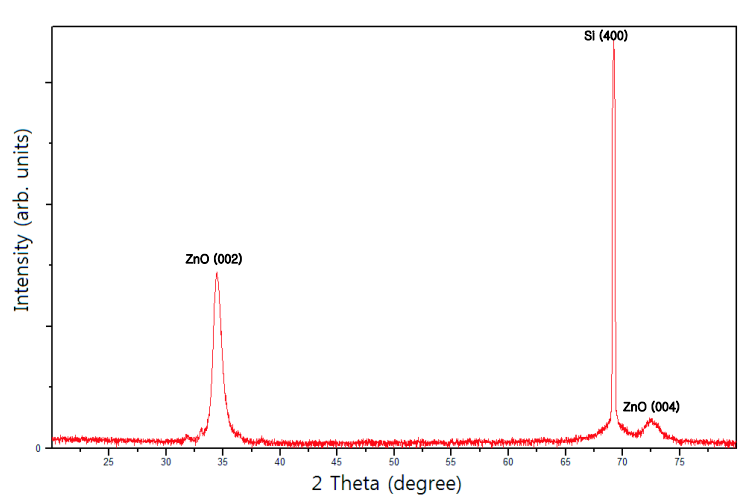

Fig. 3. XRD pattern of the $\mathrm{ZnO}$ seed layer deposited on the silicon substrate.

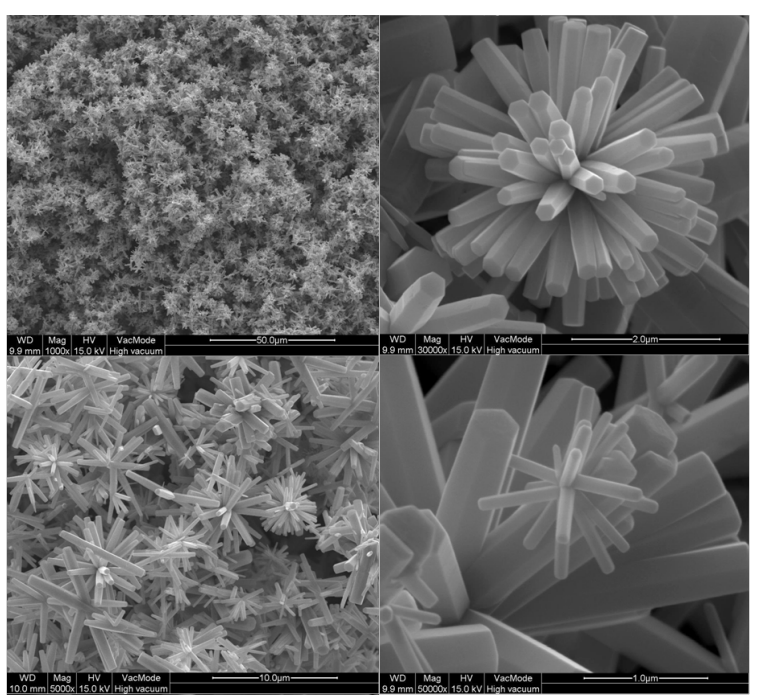

Fig. 4. SEM images of hydrothermally grown $\mathrm{ZnO}$ nanowhiskers arrays.

width at half maximum (FWHM) of the peak was 0.4488. $\mathrm{ZnO}$ nanowhisker was synthesized from the deposited $\mathrm{ZnO}$ seed layer using the hydrothermal method. The sensor was then dipped into a solution containing $0.1 \mathrm{~mol}$ zinc nitrate hexahydrate $\left(\mathrm{Zn}\left(\mathrm{NO}_{3}\right)_{2} \cdot 6 \mathrm{H}_{2} \mathrm{O}\right), 0.1 \mathrm{~mol}$ hexamethylene tetramine $\left(\mathrm{C}_{6} \mathrm{H}_{12} \mathrm{~N}_{4}\right)$ and polyethylenimine $\left(\left(\mathrm{C}_{2} \mathrm{H}_{5} \mathrm{~N}\right)_{\mathrm{n}}\right)$ and heated on a hot plate. The temperature was set to $90^{\circ} \mathrm{C}$, and the total time of synthesis was 24 hours. A temperature sensor was used to measure temperature during synthesis, and the temperature range was $90 \pm 1.5^{\circ} \mathrm{C}$. The sensor was then cleaned with ethanol and DI water and dried for 24 hours in a $90^{\circ} \mathrm{C}$ oven. To enhance the methane gas sensing property, Pd and Ag materials were evaporated for the thickness of $20 \AA$ using co-deposition. After drying, the sensor was produced in a $600^{\circ} \mathrm{C}$ nitrogen atmosphere for 30 minutes each. The $\mathrm{ZnO}$ nanowhisker grown by the proposed method was analyzed by SEM image, and shown in Fig. 4 .

\section{RESULTS AND DISCUSSION}

\subsection{Microheater heating and power consumption properties}

To measure the energy required for the microheater to reach the operating temperature, the operating voltage was varied with 


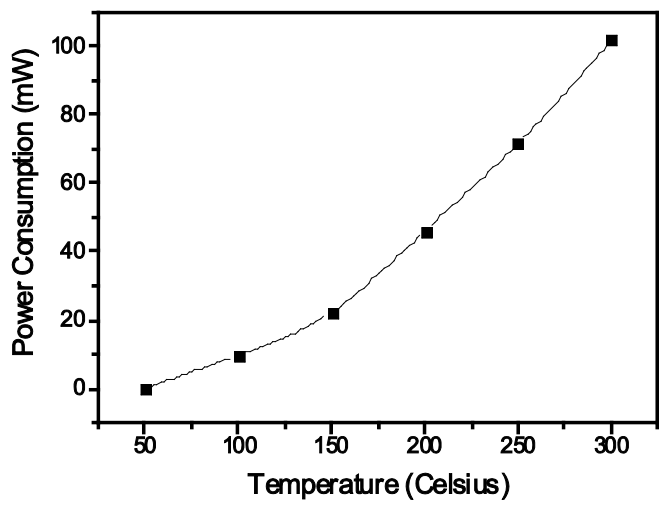

Fig. 5. Power Consumption of microheater with temperature.

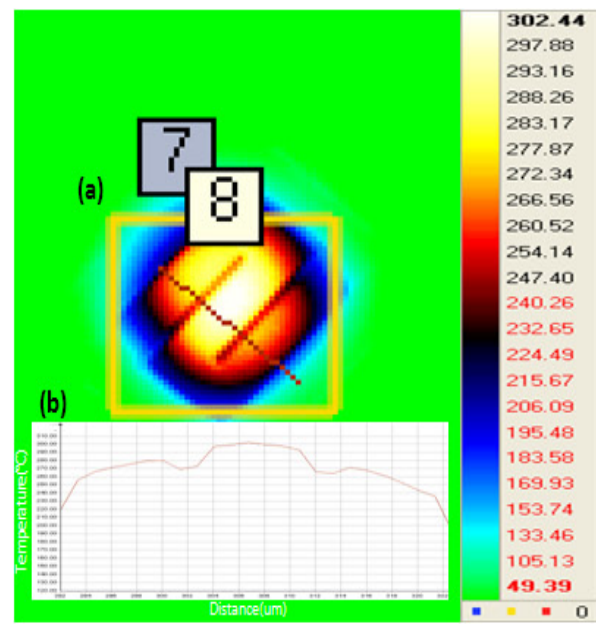

Fig. 6. Temperature profile of microheater at $2.2 \mathrm{~V}$.

temperature up to $300^{\circ} \mathrm{C}$. Figure 5 shows the power consumption of the microheater in different temperatures. The Pt microheater had a power consumption of $102 \mathrm{~mW}$ and thermal efficiency of $2.94^{\circ} \mathrm{C} / \mathrm{mW}$ at $300^{\circ} \mathrm{C}$ temperature. Figure 5 shows the temperature profile of the microheater when a $2.2 \mathrm{~V}$ operating voltage is applied. The picture was taken using an infrared thermo. Figure 6 (a) shows that most of the heat is concentrated near the origin of heating because of the membrane's superior insulation quality. Figure 6(b) graphically displays the temperature profile of the microheater where the heat dissipates from the center of the heater to the outer diaphragm. The center of the heater reached a maximum temperature of $302^{\circ} \mathrm{C}$ and the outer-most boundaries reached a minimum temperature of $220^{\circ} \mathrm{C}$. The conformation of the heater was a strip line that had a line width of $20 \mu \mathrm{m}$ and line gap of $4.5 \mu \mathrm{m}$. The temperature difference between the lines was $30^{\circ} \mathrm{C}$ at maximum and the average temperature of the microheater was about $260^{\circ} \mathrm{C}$. An operating voltage of $2.2 \mathrm{~V}$ showed a $5 \%$ error rate under conditions of $250^{\circ} \mathrm{C}$.

\subsection{Methane gas sensing properties}

The ZnO nanowhisker-based gas sensor was tested for its sensing property of methane gas in different concentrations $(5,10$, $50,100 \mathrm{ppm}$ ) and in different temperatures (from $100^{\circ} \mathrm{C}$ to $300^{\circ} \mathrm{C}$ by increments of $50^{\circ} \mathrm{C}$ ). Sensitivity was measured by injecting the gas into atmospheric air. As in Equation (1), the difference between sensor resistivity in air $\left(\mathrm{R}_{\mathrm{a}}\right)$ and sensor resistivity during gas reaction $\left(\mathrm{R}_{\mathrm{g}}\right)$ was calculated against the resistivity in air.

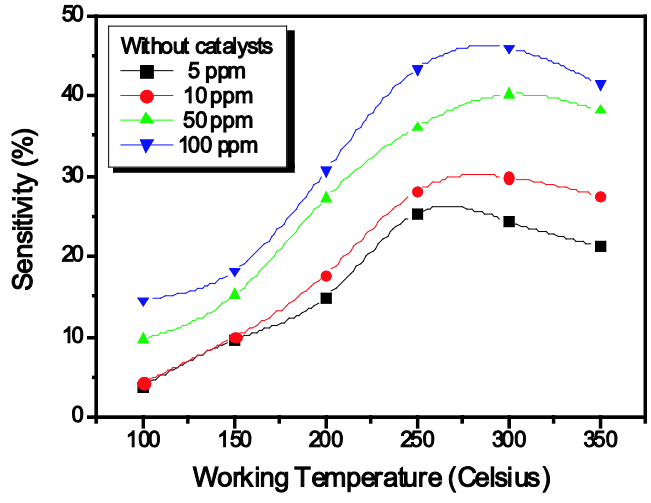

Fig. 7. Sensitivity of the $\mathrm{ZnO}$ nanoshisker sensor without catalysts as a function of temperature for various methane concentrations.

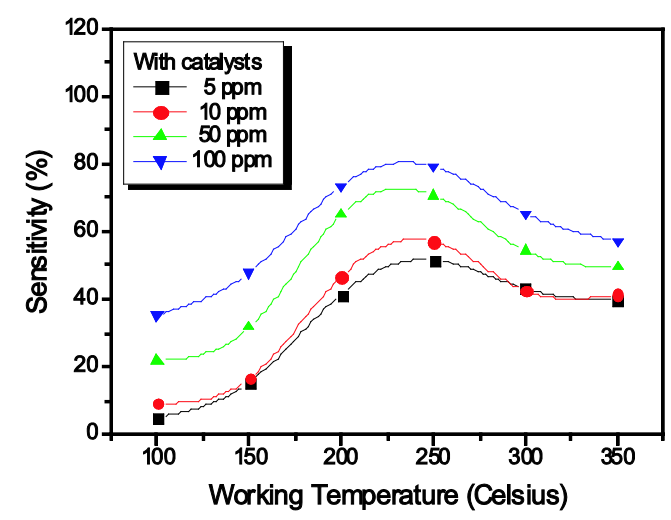

Fig. 8. Sensitivity of the $\mathrm{ZnO}$ nanowhisker sensor with $\mathrm{Pd}$ and $\mathrm{Ag}$ catalysts as a function of temperature for various methane concentrations.

$$
S=\frac{\left(R_{a}-R_{g}\right)}{R_{a}} \times 100[\%]
$$

Figures 7 and 8 show the operating temperatures of the $\mathrm{ZnO}$ nanowhisker sensor and the (Pd, Ag)-evaporated catalysis sensor against the sensing property for different methane concentrations. $\mathrm{ZnO}$ nanowhisker sensor, sensitivity appeared to increase as the operating temperature and the methane concentration increased. In relatively high temperatures $\left(>200^{\circ} \mathrm{C}\right)$ and high concentrations ( $>50 \mathrm{ppm}$ ), the sensitivity was about $30 \sim 45 \%$. For the $\mathrm{ZnO}$ nanowhisker sensor with catalysts (Pd, Ag), sensitivity increased as the operating temperature and gas concentration increased. In relatively high temperatures $\left(>200^{\circ} \mathrm{C}\right)$ and high concentrations ( $>50 \mathrm{ppm}$ ), the sensitivity was about 50 80\%. However, in operating temperature over $300^{\circ} \mathrm{C}$, sensitivity was reduced $(\sim 15 \%)$. Such phenomenon can be explained by the results from Yamazoe's research. The speed of adhesion to and detachment of methane gas from oxide semiconductor surfaces increases as the temperature increases, until it reaches a specific temperature point where the rate reaches its maximum. The optimal sensitivity and sensing rate depends on the rate of adhesion to and detachment of gas molecules from the surfaces of the sensor [13].

The sensitivity of the catalysts (Pd, Ag) sensor was 1.8-fold higher than that of the $\mathrm{ZnO}$ nanowhisker sensor. According to Kohl's research, methane gas separates into methyl group and hydrogen as a result of hydrogen bonding at the membrane 
surface, and the bonded hydrogen atoms create a hydrogen molecule.

$$
\begin{aligned}
& \mathrm{CH}_{4 g a s} \leftrightarrow \mathrm{CH}_{3 a d s}+H_{a d s} \\
& H_{a d s}+H_{a d s} \rightarrow \mathrm{H}_{2}
\end{aligned}
$$

Hydrogen molecules react with oxygen on the Pd, Ag surface to produce $\mathrm{H}_{2} \mathrm{O}$. This organic radical goes through a series of chain reactions to finally produce $\mathrm{CO}_{2}$. Metals, such as $\mathrm{Pd}$ and $\mathrm{Ag}$, act as catalysts in oxidizing flammable gases, such as methane, which greatly increase the rate of reaction $[7,13]$. Sensitivity increased as concentration increased; however, from 5 ppm to $10 \mathrm{ppm}$, only about a $3 \%$ average increase was shown, whereas higher concentrations yielded a higher increase rate (17\%, 30\%). The operating temperature of $250^{\circ} \mathrm{C}$ was found to be the optimal temperature for all concentrations of gas. For concentrations higher than $100 \mathrm{ppm}$, the relatively low operating temperature of $150^{\circ} \mathrm{C}$, yielded a sensitivity of $64 \%$, which is about $81 \%$ of the optimal temperature value $\left(79 \% @ 250{ }^{\circ} \mathrm{C}\right)$. The power consumption under $150^{\circ} \mathrm{C}$ and $250^{\circ} \mathrm{C}$ operating temperatures was $25 \mathrm{~mW}$ and $72 \mathrm{~mW}$, respectively. An operating temperature of $150^{\circ} \mathrm{C}$ only used a third of the power required for an operating temperature of $250^{\circ} \mathrm{C}$.

\section{CONCLUSION}

The MEMS process was used to produce a $2.6 \mathrm{~mm} \times 2.6 \mathrm{~mm}$ sensor with $20 \mu \mathrm{m}$ heater lines and $4.5 \mu \mathrm{m}$ gaps on a membrane of $800 \mu \mathrm{m} \times 800 \mu \mathrm{m}$ surface area as a strip line form. A gas sensor with internalized Pt microheater was evaporated from a $\mathrm{ZnO}$ seedlayer using PLD, and $\mathrm{ZnO}$ nanowhisker was developed by hydrothermal synthesis as the sensing material. To enhance the sensing property of methane gas, Pd and Ag were used as catalysts, and the sensing property was confirmed by exposing the sensor to different concentrations of methane gas under different operating temperatures. As a result of the measurement, an operation temperature of $250^{\circ} \mathrm{C}$ was found to be optimal under all concentrations of gas. When the methane gas concentration was $100 \mathrm{ppm}$ and the operating temperature was $250^{\circ} \mathrm{C}$, the sensitivity was found to be $79 \%$ and the power consumption was $72 \mathrm{~mW}$. When the operating temperature was $150^{\circ} \mathrm{C}$, the power consumption was $25 \mathrm{~mW}$ and the sensitivity was $64 \%$. This result indicated that a $150^{\circ} \mathrm{C}$ operating temperature consumed only a third of the power of the maximum sensitivity condition, but still showed superb sensitivity.

\section{REFERENCES}

[1] Q. Schiermeier, Nature 439, 128 (2006) [DOI: 10.1038/439128a].

[2] K. D. Mitzner, J. Sternhagen, and D. W. Galipeau, Sensor. Actuat. B 93, 92 (2003) [DOI: 10.1016/S0925-4005(03)00244-2].

[3] J. S. Suehle, R. E. Cavicchi, M. Gaitan, and S. Semancik, IEEE Electron Device Letters 14, 118 (1993) [DOI: 10.1109/55.215130].

[4] C. Lu, Z. Chen, and V. Singh, Sensor. Actuat. B 146, 145 (2010) [DOI: 10.1016/j.snb.2010.02.034].

[5] S. Santra, P. K. Guha, S. Z. Ali, P. Hiralal, H. E. Unalan, J. A. Convington, G. A. J. Amaratunga, W. I. Milne, J. W. Gardner, and F. Udrea, Sensor. Actuat. B 146, 559 (2010) [DOI: 10.1016/ j.snb.2010.01.009].

[6] L. V. Thong, N. D. Hoa, D. T. Thanh Le, D. T. Viet, P. D. Tam, A. T. Le, and N. V. Hieu, Sensor. Actuat. B 146, 361 (2010) [DOI: 10.1016/j.snb.2010.02.054].

[7] K. Chatterjee, S. Chatterjee, A. Banerjee, M. Raut, N. C. Pal, A. Sen, and H. S. Maiti, Materials Chemistry and Physics 81, 33 (2003) [DOI: 10.1016/S0254-0584(03)00145-7].

[8] D. Kohl, J. Phys. D: Appl. Phys. 34, 125 (2001) [DOI: 10.1088/0022-3727/34/19/201].

[9] J. Puigcorbe, D. Vogel, B. Michel, A. Vila, I. Gracia, C. Cane and J. R. Morante, J. Micromech. Microeng. 13, 548 (2003) [DOI: 10.1088/0960-1317/13/5/304].

[10] E. Comini, G. Faglia, G. Sberveglieri, Z. Pan, and Z. L. Wang, Appl. Phys. Lett. 81, 1869 (2002) [DOI: 10.1063/1.1504867].

[11] Z. L. Wang, Adv. Mater. 15, 432 (2003) [DOI: 0935-9648/03/05030433].

[12] C. M. Carney, S. Yoo, and S. A. Akbar, Sensor. Actuat. B 108, 29 (2005) [DOI: 10.1016/j.snb.2004.11.058].

[13] N. Yamazoe, J. Fuchigami, M. Kishikawa, and T. Seiyama, Surface Science 86, 335 (1979) [DOI: 10.1016/0039-6028(79)90411-4]. 